\title{
Ejercicio académico
}

\section{Álvaro Ernesto Pleités}

$\mathrm{P}$ resentamos este nuevo volumen de Crea Ciencia, nuestra vía académico-científica oficial de comunicación. Ofrecemos a los profesionales del área de la salud espacios para que sus investigaciones sean publicadas. Todo proceso de investigación no es completo si los resultados que resuelven problemas, y agregan conocimiento antes no imaginado, no publicados. Me refiero a publicación científica, en donde debemos hacer el mejor esfuerzo para redactar el artículo, de manera que cumpla con las normas internacionalmente aceptadas, para el área de salud.

Como Editorial UEES, mantenemos este esfuerzo para promover, publicar y divulgar, inicialmente la producción de los profesionales de la Universidad Evangélica, pero, poco a poco se han recibido artículos de muy buena calidad, de profesionales externos, los cuales han sido incluidos en esta edición. Agradecemos los esfuerzos realizados por los profesionales al completar su investigación con el artículo para publicación. Este es otro aprendizaje que todos los profesionales debemos poseer, para que los esfuerzos realizados no terminen en un muy buen ejercicio académico sin impacto social.

Para quienes aún no han experimentado el proceso de Investigación, y escribir un artículo para publicación, les invitamos a acercarse a nuestra Universidad, y aprovechar las diferentes oportunidades de capacitación en investigación científica.

1 doctor en medicina, Vice Rector de Investigación y Proyección Social de la Universidad Evangélica de El Salvador e-mail: alvaro.pleites@uees.edu.sv 